International Journal of

Environmental Research and

Public Health

ISSN 1660-4601

www.mdpi.com/journal/ijerph

Article

\title{
Effect of Shisha (Waterpipe) Smoking on Lung Functions and Fractional Exhaled Nitric Oxide (FeNO) among Saudi Young Adult Shisha Smokers
}

\section{Sultan Ayoub Meo *, Khaled Ahmed AlShehri, Bader Bandar AlHarbi, Omar Rayyan Barayyan, Abdulrahman Salem Bawazir, Omar Abdulmohsin Alanazi and Ahmed Raad Al-Zuhair}

Department of Physiology, College of Medicine, King Saud University, P.O. Box 2925, Riyadh 11461 Saudi Arabia; E-Mails: K_a_Z_h@hotmail.com (K.A.A.); Bdr.alharbi.431@gmail.com (B.B.A.); Mr.omar.b@hotmail.com (O.R.B.); Dr.a.bwz@gmail.com (A.S.B.); Dr-3umar92@hotmail.com (O.A.A.); Ahmed-alzuhair@hotmail.com (A.R.A.-Z.)

* Author to whom correspondence should be addressed; E-Mails: smeo@ksu.edu.sa or sultanmeo@ hotmail.com; Tel.: +96-611-467-1604; Fax.: +96-611-467-2567.

Received: 15 June 2014; in revised form: 2 September 2014 / Accepted: 3 September 2014 / Published: 17 September 2014

\begin{abstract}
Shisha (waterpipe) smoking is becoming a more prevalent form of tobacco consumption, and is growing worldwide, particularly among the young generation in the Middle East. This cross-sectional study aimed to determine the effects of shisha smoking on lung functions and Fractional Exhaled Nitric Oxide (FeNO) among Saudi young adults. We recruited 146 apparently healthy male subjects (73 control and 73 shisha smokers). The exposed group consisted of male shisha smokers, with mean age $21.54 \pm 0.41$ (mean \pm SEM) range 17-33 years. The control group consisted of similar number (73) of non-smokers with mean age $21.36 \pm 0.19$ (mean \pm SEM) range 18-28 years. Between the groups we considered the factors like age, height, weight, gender, ethnicity and socioeconomic status to estimate the impact of shisha smoking on lung function and fractional exhaled nitric oxide. Lung function test was performed by using an Spirovit-SP-1 Electronic Spirometer. Fractional Exhaled Nitric Oxide (FeNO) was measured by using Niox Mino. A significant decrease in lung function parameters FEV1, FEV1/FVC Ratio, FEF-25\%, FEF-50\%, FEF-75\% and FEF-75-85\% was found among shisha smokers relative to their control group. There was also a significant reduction in the Fractional Exhaled Nitric Oxide among Shisha smokers compared to control group.
\end{abstract}


Keywords: lung function; fractional exhaled nitric oxide; Shisha smoking

\section{Introduction}

Shisha smoking is known by a various names, including waterpipe, narghile, arghile, ghoza, borry, shui yan dai, hubble bubble and hookah smoking [1]. Shisha smoking originated in India, South Africa, Persia, and Ethiopia and currently is a common practice in Arab countries [2]. Its use is frequent among the youth, high income and urban population, especially in posh localities [3]. It has steadily been spreading among the various age groups, but especially among adolescents around the world, and gained more popularity in the Middle East in the form of Shisha cafe culture. The prevalence of Shisha smoking ranges from 5\%-17\% in American youths, 6\%-34\% among Middle Eastern adolescents [4], and in some studies the prevalence of Shisha smokers has been reported to be up to $44.3 \%$ among immigrants in the U.S. [5].

Shisha smoke contains large quantities of flavored nicotine, fine and ultrafine PM, carbon monoxide, polycyclic aromatic hydrocarbons, volatile aldehydes, phenolic compounds and carcinogenic PAH [6-11], and heavy metals, including arsenic and lead. Shisha smokers use tobacco flavored with apple, plum, coconut, mango, mint, strawberry and cola, which makes the act of smoking more attractive, sweet and aromatic than cigarette smoking.

The most common types of tobacco used in the Shisha smoking are: Maassel, Ajami, Tumbak and Jurak [12]. The nicotine content of water pipe tobacco is $2 \%-4 \%$ and carbon monoxide concentration is $0.34 \%-1.40 \%$. Shisha smoking sessions usually last for 20-80 min [13]. The smokers are thus exposed to much more smoke over a longer period of time. The smoker takes 50-200 puffs; inhales $0.15-1 \mathrm{~L}$ of smoke in one session of Shisha which is equivalent to smoke of about 100 cigarettes $[12,13]$.

Lung function tests are a widely used tool to describe the effects of obstruction or restriction on lung function. It is a powerful diagnostic tool that plays a significant role in the diagnosis of early lung damage. It is also used to monitor the therapeutic efficacy of various treatment regimens and the course of the disease. The spirometric parameters have gained more popularity when it has been reported that Forced Vital Capacity (FVC), Forced Expiratory Volume in $1 \mathrm{~s}$ (FEV1), and FEV1/FVC Ratio are essential for the diagnosis of obstructive and restrictive respiratory illness [14]. Similarly, Measurement of Fractional Nitric Oxide (NO) in exhaled breath (FeNO) is a simple, safe, reliable and non-invasive tool in assessing the severity of pulmonary inflammation and asthma [15].

Cigarette smoking-related research and control efforts have generally been focused on traditional cigarettes, while little research exists on Shisha smoking and most of the literature fails to consider the physiological parameters including age, height, weight, gender, ethnicity and socio-economical matching between the groups. In order to address the emerging health risk, the present study aimed to determine the effects of Shisha smoking on lung function and Fractional Exhaled Nitric Oxide (FeNO) among young Saudi adults. 


\section{Subjects and Methods}

\subsection{Subjects}

All subjects gave their informed consent for inclusion before they participated in the study. The study was conducted in accordance with the Declaration of Helsinki, and the protocol was approved by the Ethics Committee of College of Medicine Research Centre, King Saud University, Riyadh, KSA (CMED-305-MB7).

This cross sectional study was conducted in the Department of Physiology, College of Medicine, King Saud University, Riyadh, Saudi Arabia during the period January 2013-Decemeber 2013. Between the groups age, height, weight, gender, ethnicity and socioeconomic status factors were considered to estimate the impact of Shisha smoking on lung function and fractional exhaled nitric oxide. For this study, 146 participants (73 Shisha smokers and 73 non Shisha smokers) were selected. A detailed interview of the subjects was conducted, followed by history taking and clinical examination to determine whether to include him in the study or not. All the participants were questioned with regards to cigarette, Shisha smoking and other tobacco product consumption. The Shisha exposed group consisted of 73 volunteer, male subjects. It consisted of university students, clerks, secretarial staff and salespersons. The control group was selected in a similar way. Initially, 100 subjects were interviewed, clinical history and examination were conducted, and finally 73 volunteer, healthy men were selected. The control group primarily consisted of university students plus receptionists, secretaries, porters and research assistants.

\subsection{Exclusion Criteria}

Subjects with known cases of gross anemia, diabetes mellitus, chronic obstructive pulmonary diseases, bronchial asthma, malignancy, drug addicts and tobacco smokers (other than Shisha) were excluded. The subjects who were regularly exercising vigorously or working in any industry which generates dust or fumes were also excluded from the study [16].

\subsection{Methods: Lung Function Test (Spirometry)}

To assess Lung Function in subjects spirometry was performed using a SPIROVIT SP-1 (Schiller AG, Baar, Switzerland) instrument. The following lung function parameters were included: Forced Vital Capacity (FVC), Forced Expiratory Volume in first second (FEV1), Forced Expiratory Ratio (FEV1/FVC\%), Peak Expiratory Flow (PEF), Forced Expiratory Flow (FEF-25\%), Forced Expiratory Flow (FEF-50\%), Forced Expiratory Flow (FEF-75\%), Forced Expiratory Flow (FEF-25-75\%) and Forced Expiratory Flow (FEF-75-85\%). The defined techniques in executing various lung function tests for the present study were based on the operation manual of instrument with special reference to the official statement of the American Thoracic Society of Standardization 2005 [17]. After taking a detailed history and anthropometric data, the subjects were informed about the whole maneuver. The subjects were encouraged to practice this maneuver before doing the pulmonary function test. The participants were instructed three times, and the test was performed with the subject in the standing position with a nose clip and best values were taken. The subject was asked to 
inhale to the maximum and exhale completely as fast as possible and make sure to get all the air out of the lungs. A new disposable sterile mouth piece was used for each participant to prevent any cross infection.

\subsection{Fractional Exhaled Nitric Oxide (FeNO)}

Fractional Exhaled Nitric Oxide (FeNO) concentration was measured by using a Niox Mino unit, (Aerocrine, Solna, Sweden). The FeNO device was pre-calibrated for a predetermined life span (300 measurements) by the manufacturer; hence the device did not require re-calibrations in the field. Tests were carried out at a fixed time of the day to minimize the diurnal variation of FeNO concentration [18]. The defined techniques in executing FeNO test for the present study were based on the operation manual of the instrument with special reference to the official statement of the American Thoracic Society/ERS Standardization procedure for FENO measurements [19]. After taking a detailed history and anthropometric data, the subjects were informed about the whole maneuver. All measurements of the Shisha smokers were conducted in the adjacent room of Shisha cafe and for control group all measurements were performed in the Physiology lab of College of Medicine, KSU. The tests were performed with the subject in the standing position while using a nose clip. The results were recorded through a laptop computer attached to the Niox Mino, Aerocrine, Solna, Sweden.

\subsection{Statistical Analysis}

The data were entered into the computer and analyzed by using the Statistical Package for Social Sciences (SPSS for Windows, version 20.0). Unpaired Student's $t$-test (parametric test) was applied to test the difference of the means between the two quantitative variables. The level of significance was assumed at $p<0.05$.

\section{Results and Discussion}

Table 1 summarizes the comparison of the anthropometric variables and lung function parameters between Shisha smokers and their control group. The mean age of Shisha smokers was $21.54 \pm 0.41$ (mean \pm SEM) years, height $172.68 \pm 0.76$ (mean \pm SEM) $\mathrm{cm}$, weight $76.26 \pm 2.39$ (mean \pm SEM) $\mathrm{kg}$. However, for control group the mean age $21.36 \pm 0.19$ (mean \pm SEM) years, height $173.71 \pm 1.03$ (mean $\pm \mathrm{SEM}$ ) $\mathrm{cm}$ and weight was $72.84 \pm 1.48$ (mean $\pm \mathrm{SEM}$ ) $\mathrm{kg}$. There was a significant decline in the lung function parameters of Shisha smokers including FEV1 $(p=0.0001)$, FEV1/FVC Ratio $(p=0.0001)$, FEF-25\% $(p=0.005)$, FEF-50\% $(p=0.0001)$, FEF-75\% $(p=0.0001)$, and FEF-75-85\% ( $p=0.010)$ compared to their age, height, weight and ethnicity matched non-Shisha smoker subjects.

However, there was no reduction in FVC, FEF-25-75\% and PEF. Moreover, in the present study, we found that fractional exhaled nitric oxide (FeNO) was also significantly decreased in Shisha smokers $(p=0.022)$, compared to their control subjects. The mean duration of Shisha smokers was $2.97 \pm 0.22$ years (mean \pm SEM), range $1-8$ years.

Table 2 presents the mean values of anthropometric variables and FeNO level for the Shisha smokers and the control group. The statistical comparisons of the matching variables including age, 
height and weight, ethnicity and socioeconomic status were similar for both groups. Mean FeNO of Shisha smokers was $23.97 \pm 2.12 \mathrm{ppb}$ compared to their control group $31.38 \pm 2.38 \mathrm{ppb}$. The FENO was significantly decreased in Shisha smokers $(p=0.022)$ compared to their control group.

Table 1. Comparison of various lung function parameters between Shisha Smokers compared to their matched control group.

\begin{tabular}{llll}
\hline Parameters & Shisha Group $(\boldsymbol{n}=\mathbf{7 3})$ & Control Group $(\boldsymbol{n}=\mathbf{7 3})$ & $\boldsymbol{p}$ Values \\
\hline Age (years) & $21.54 \pm 0.41$ & $21.36 \pm 0.19$ years & 0.697 \\
Height (cm) & $172.68 \pm 0.76$ & $173.71 \pm 1.03 \mathrm{~cm}$ & 0.427 \\
Weight $(\mathrm{kg})$ & $76.26 \pm 2.39$ & $72.84 \pm 1.48 \mathrm{~kg}$ & 0.227 \\
FVC $(\mathrm{L})$ & $5.76 \pm 0.21$ & $5.54 \pm 0.11$ & 0.351 \\
FEV1 (L) & $3.80 \pm 0.12$ & $4.49 \pm 0.073$ & 0.0001 \\
FEV1//FVC (\%) & $69.34 \pm 1.87$ & $82.83 \pm 1.29$ & 0.0001 \\
FEF-25\% (L/sec) & $6.04 \pm 0.25$ & $6.93 \pm 0.18$ & 0.005 \\
FEF-50\% (L/sec) & $3.13 \pm 0.19$ & $5.25 \pm 0.17$ & 0.0001 \\
FEF-75\% (L/sec) & $1.13 \pm 0.13$ & $2.56 \pm 0.13$ & 0.0001 \\
FEF-25-75\% (L/sec) & $6.86 \pm 2.23$ & $4.53 \pm 0.19$ & 0.293 \\
FEF-75-85\% (L/sec) & $1.21 \pm 0.24$ & $1.91 \pm 0.11$ & 0.010 \\
PEF (L/sec) & $7.29 \pm 0.22$ & $7.32 \pm 0.18$ & 0.895 \\
\hline
\end{tabular}

Notes: Values are presented in Mean \pm SEM

Table 2. Comparison of Fractional Exhaled Nitric Oxide (FeNO) between Shisha smokers compared to their matched control group.

\begin{tabular}{cccc}
\hline Parameters & Shisha Group & Control Group & $\boldsymbol{p}$ Values \\
\hline Age $($ years $)$ & $21.54 \pm 0.41$ & $21.36 \pm 0.19$ & 0.697 \\
Height $(\mathrm{cm})$ & $172.68 \pm 0.76$ & $173.71 \pm 1.03$ & 0.427 \\
Weight $(\mathrm{kg})$ & $76.26 \pm 2.39$ & $72.84 \pm 1.48$ & 0.227 \\
FeNO $(\mathrm{ppb})$ & $23.97 \pm 2.12$ & $31.38 \pm 2.38$ & 0.022 \\
\hline \multicolumn{5}{c}{ Note: Values are presented in Mean \pm SEM. }
\end{tabular}

\section{Discussion}

\subsection{Main Findings}

Tobacco smoking is a global public health risk causing more than 6 million deaths each year; approximately one person dies every six seconds due to tobacco [20]. Tobacco is commonly smoked in different ways including cigarette, cigar, and Shisha. Presently, Shisha smoking is gaining popularity among the young, high income and urban population of the world. It is becoming a new tobacco pandemic and severely affecting the indoor air quality and involves severe health risks [11]. Shisha smoking produces large amount of toxic ultrafine particles and carry similar health risks as smoking cigarettes [7]. In the present study, we determined the effects of Shisha smoking on lung functions and Fractional Exhaled Nitric Oxide (FeNO) among Saudi young adults. We found a significant reduction in lung function parameters FEV1, FEV1/FVC\%, FEF-25\%, FEF-50\%, FEF-75\%, FEF-75-85\% in Shisha smokers relative to their matched control group. There was also a 
significant reduction in the Fractional Exhaled Nitric Oxide (FeNO) in Shisha smokers compared to control group.

\subsection{Lung Function Tests}

Lung function test is ideally suited to describe the obstructive and restrictive pattern of respiratory diseases in various occupational and environmental settings [21-23]. It is an essential part of a respiratory function evaluation and is used to categorize the nature, severity and progression of respiratory diseases. In the present study, we found a significant reduction in lung function parameters FEV1, FEV1/FVC Ratio, FEF-25\%, FEF-50\%, FEF-75\% and FEF-75-85\% in Shisha smokers relative to their matched control group.

Al-Fayez et al. [24] reported the effects of Shisha smoking on pulmonary function test values. They found that FEV1 and FVC mean values of male Shisha smokers were significantly lower than those of non-smokers. Pulmonary function measurements demonstrate a decline pattern with age of Shisha smokers particularly in the age group 20-49. They conclude that Shisha smoking produce adverse effects on the pulmonary functions and increase the risk of developing obstructive airway disease. Similarly, in the present study we found a significant decline in lung function parameters and the pattern of lung function impairment was obstructive airway disease. This obstructive defect is documented in relatively young individuals, and after a relatively short duration of waterpipe smoking. This finding contradicts the general public belief that waterpipe smoking is safer than cigarette smoking.

Hakim et al. [25] reported the acute effects of Shisha (waterpipe) smoking on pulmonary function test results. There was a decrease in forced expiratory flow between FEF-25\% and FEF-75\% of FVC, peak expiratory flow rate. They show that waterpipe smoking causes biologic changes that might result in marked health problems. Likewise, Hawari et al. [26] conducted a study on waterpipe tobacco smokers with mean age 20.4 years, they found that forced expiratory flow over the middle half of the forced vital capacity (FEF50\%) was decreased among waterpipe tobacco smokers. Similarly, in the present study we found a significant reduction in lung function parameters FEV1, FEF-25\%, FEF-50\%, FEF-75\% and FEF-75-85\% in Shisha smokers relative to their matched control group.

Raad et al. 2011 [27] conducted a meta-analysis comparing water-pipe smokers with nonsmokers for spirometric measurements of FEV1, FVC, and FEV1/FVC Ratio. Waterpipe tobacco smokers were associated with significant reduction in FEV1, FVC and lower FEV1/FVC Ratio. Correspondingly, in the present study, in addition to other parameters, we found a significant reduction in FEV1 and FEV1/FVC Ratio in Shisha smokers relative to their matched control group.

Schünemann et al. [28] reported that waterpipe smokers were associated with a significant reduction of $\mathrm{FEV}_{1}$ and a trend toward lower $\mathrm{FVC}$ and $\mathrm{FEV}_{1} / \mathrm{FVC}$ Ratio. Boskabady et al. [29] showed a profound effect of waterpipe smoking on lung function values. They found that FVC, FEV1, MMEF, PEF, MEF-75, MEF-50, MEF-25 in waterpipe smokers were significantly lower than the corresponding values in non-smokers. Concurrently, in the present study, we found a significant reduction in FEV1, FEV1/FVC Ratio, FEF-25\%, FEF-50\%, FEF-75\% and FEF-75-85\% in Shisha smokers relative to their matched control group. 


\subsection{Fractional Exhaled Nitric Oxide (FeNO)}

Fractional exhaled nitric oxide (FeNO) is a non-invasive, widely used method for assessing the inflammatory status of the lungs with airway disease [30-33]. It has achieved great consideration in the diagnosis of respiratory diseases and become highly popular parameter both in respiratory researchers and clinicians. It has recently been standardized by both American Thoracic Society and European Respiratory Society (ATS/ERS-2005) [33]. FeNO is an essential marker of eosinophilic airway inflammation, markedly elevated in bronchial asthma [32], chronic airway inflammation and allergic rhinitis [33]. It is recognized as a precise, reproducible and noninvasive diagnostic test for airway disease [34]. It is influenced by variety of patho-physiological processes in the upper and lower airways, tobacco smoking [32] and working exposure in environmental and occupational industries which cause air pollution [16,17,35-39].

She et al. [40] found the significantly increased risk of COPD in Chinese waterpipe smokers compared to never-smoking controls. Similarly based on the results of present study we found that Shisha smoking is associated with chronic obstructive pulmonary diseases (COPD).

The main finding of the present study is that Shisha smoking is associated with a reduction in FeNo levels. Few studies have reported reduced levels of FeNO after both short- and long-term cigarette smoking [41]. Possible mechanisms include down regulation of endothelial and inducible nitric oxide synthase, and rapid conversion of nitric oxide to peroxynitrite by reactive oxygen and nitrogen species $[42,43]$.

Smoking is associated with a reduction in exhaled nitric oxide (FeNO) levels. There is, however, limited knowledge relating to the smoking-induced changes in production of NO in different compartments of the airways [44]. In the present study, we found a significant reduction in Fractional Exhaled Nitric Oxide (FeNO) in Shisha smokers compared to control group. In parallel to our findings, Hakim et al., reported the effects of waterpipe smoking on fractional exhaled nitric oxide (FeNO) levels. There was a decrease in FeNO levels. They showed that waterpipe smoking causes biologic changes that might result in marked health problems.

\subsection{What This Study Adds}

Shisha (waterpipe) smoking is a swiftly growing global epidemic and causes serious complications. Shisha smoking significantly decreases the lung function parameters and Fractional Exhaled Nitric Oxide (FeNO) compared to their matched control. It affects the young subjects even after a relatively short duration of exposure. The present study is one of the first studies to investigate effect of Shisha smoking on lung functions and exhaled nitric oxide. This research provides awareness to the community and to the health officials regarding the effects of smoking Shisha on lung function and Fractional Exhaled Nitric Oxide (FeNO). The clinical use of FeNO for diagnostic purposes in waterpipe smokers should be taken into account and its correlation with PFTs in clinical context is highly recommended. Furthermore, health officials must implement suitable policies to minimize the use of Shisha smoking. 


\subsection{Study Strengths and Limitations}

In this study, we selected a very important topic of current interest, and determined the effects of Shisha smoking on lung function and FeNO. FeNo is novel marker of eosinophilic airway inflammation. While little research exists on Shisha smoking, lung function and FeNO, the literature has failed to consider key physiological parameters including age, height, weight, gender, ethnicity and socio-economical matching. Moreover, we used well-established exclusion criteria to determine the impact of Shisha smoking on lung function and FeNO. The limitations of the present study include lack of specific smoke exposure assessment and the relatively small sample size.

\section{Conclusions}

It is concluded that, lung function parameters FEV1, FEV1/FVC Ratio, FEF-25\%, FEF-50\%, FEF-75\% and FEF-75-85\% were significantly decrease in Shisha smokers relative to their control group. There was also a significant reduction in the Fractional Exhaled Nitric Oxide among Shisha smokers compared to control group.

\section{Acknowledgements}

The authors are thankful to the Deanship of Scientific Research, King Saud University, Riyadh, Saudi Arabia for supporting the work through research group project (RGP-VPP 181). The authors are also thankful to the Department of Physiology and Department of Family and Community Medicine, College of Medicine, King Saud University, Riyadh, Saudi Arabia for their technical support.

\section{Author Contributions}

Sultan Ayoub Meo brings the ideas, study design, manuscript writing and supervision of the research project, Khaled Ahmed AlShehri, Bader Bandar AlHarbi provides insight for research formulation, literature guidance and data collection, Omar Rayyan Barayyan, Abdulrahman Salem Bawazir, Omar Abdulmohsin Alanazi, and Ahmed Raad Al-Zuhair were involved in data collection, analysis and literature search.

\section{Conflicts of Interest}

The authors declare no conflict of interest.

\section{References}

1. Maziak, W.; Ward, K.D.; Soweid, R.A.A.; Eissenberg, T. Tobacco smoking using a waterpipe: A re-emerging strain in a global epidemic. Tob. Control. 2004, 13, 327-333.

2. Kiter, G.; Ucan, E.S.; Ceylan, E. Water-pipe smoking and pulmonary functions. Respirator. Med. 2000, 9, 891-894.

3. Sohn, R.M.; Shishani, B.K.; Okada, R.A.; Froelicher, E.S. Approaches to Smoking Cessation in a Cardiovascular Population, 1st ed.; Ellen, A.D., Ed.; Springer: New York, NY, USA, 2012; pp. 345-372. 
4. Maziak, W. The global epidemic of waterpipe smoking. Addict. Behav. 2011, 36, 1-5.

5. Arfken, C.L.; Abu-Ras, W.; Ahmed, S. Pilot study of waterpipe tobacco smoking among U.S. Muslim college students. J. Relig. Health. 2014, doi:10.1007/s10943-014-9871-x.

6. Shihadeh, A.; Saleh, R. Polycyclic aromatic hydrocarbons, carbon monoxide, "tar", and nicotine in the mainstream smoke aerosol of the narghile water pipe. Food Chem. Toxicol. 2005, 43, 655-661.

7. Monn, C.; Kindler, P.; Meile, A.; Brandli, O. Ultrafine particle emissions from waterpipes. Tob. Control 2007, 16, 390-393.

8. $\quad$ Daher, N.; Saleh, R.; Jaroudi, E.; Sheheitli, H.; Badr, T.; Sepetdjian, E.; Al Rashidi, M.; Saliba, N.; Shihadeh, A. Comparison of carcinogen, carbon monoxide, and ultrafine particle emissions from narghile waterpipe and cigarette smoking: Sidestream smoke measurements and assessment of second-hand smoke emission factors. Atmos. Environ. 2010, 44, 8-14.

9. Sepetdjian, E.; Shihadeh, A.; Saliba, N.A. Measurement of 16 polycyclic aromatic hydrocarbons in narghile waterpipe tobacco smoke. Food Chem. Toxicol. 2008, 46, 1582-1590.

10. Sepetdjian, E.; Abdul Halim, R.; Salman, R.; Jaroudi, E.; Shihadeh, A.; Saliba, N.A. Phenolic compounds in particles of mainstream waterpipe smoke. Nicotine Tob. Res. 2013, 15, 1107-1112.

11. Torrey, C.M.; Moon, K.A.; Williams, D.A.; Green, T.; Cohen, J.E.; Navas-Acien, A.; Breysse, P.N. Waterpipe cafes in Baltimore, Maryland: Carbon monoxide, particulate matter, and nicotine exposure. J. Expo. Sci. Environ. Epidemiol. 2014, doi:10.1038/jes.2014.19.

12. Knishkowy, B.; Amitai, Y. Water-pipe (narghile) smoking: An emerging health risk behavior. Pediatrics 2005, 116, 113-119.

13. Shafagoj, Y.A.; Mohammad, F.I. Levels of maximum endexpiratory carbon-monoxide and certain cardio vascular parameters following hubble-bubble smoking. Saudi. Med. J. 2002, 23, 953-958.

14. Meo, S.A. Significance of spirometry in diabetic patients. Int. J. Diab. Mellit. 2010, 2, 47-50.

15. Dweik, R.A.; Boggs, P.B.; Erzurum, S.C.; Irvin, C.G.; Leigh, M.W.; Lundberg, J.O.; Olin, A.C.; Plummer, A.L.; Taylor, D.R. American thoracic society committee on interpretation of exhaled nitric oxide levels (FENO) for clinical applications. An official ATS clinical practice guideline: Interpretation of exhaled nitric oxide levels (FENO) for clinical applications. Amer. J. Respir. Crit. Care Med. 2011, 184, 602-615.

16. Meo, S.A.; Alsaaran, M.K. Alshehri, effect of exposure to cement dust on fractional exhaled nitric oxide (FeNO) in non-smoking cement mill workers. Eur. Rev. Med. Pharmacol. Sci. 2014, 18, 1458-1464.

17. Miller, M.R.; Hankinson, J.; Brusasco, V.; Burgos, F.; Casaburi, R.; Coates, A.; Crapo, R.; Enright, P.; van der Grinten, C.P.; Gustafsson, P.; et al. ATS/ERS task force standardisation of spirometry. Eur. Respir. J. 2005, 26, 319-338.

18. Stark, H.; Purokivi, M.; Kiviranta, J.; Randell, J.; Tukiainen, H. Short-term and seasonal variations of exhaled and nasal NO in healthy subjects. Respir. Med. 2007, 101, 265-271.

19. Raed, A.; Dweik, P.B.; Boggs, S.C.; Erzurum, C.G.; Irvinmw Leigh, J.O.; Lundberg, A.C.; Olin, A.L.; Plummer, D.; Taylor, R. An official ATS clinical practice guideline: Interpretation of exhaled nitric oxide levels (FeNO) for clinical applications. Amer. J. Respir. Crit. Care Med. 2011, 184, 602-615. 
20. World Health Organization. Tobacco, Key Facts. Available Online: http://www.who.int/ mediacentre/factsheets/fs339/en (accessed on 12 April 2014).

21. Meo, S.A. Lung function in Pakistani wood workers. Int. J. Environ. Health Res. 2006, 16, 193-203.

22. Meo, S.A. Dose responses of years of exposure on lung function in flour mill workers. J. Occup. Health 2004, 46, 187-191.

23. Meo, S.A.; Al-Drees, A.M.; Al Masri, A.A.; Al Rouq, F.; Azeem, M.A. Effect of duration of exposure to cement dust on respiratory function of non-smoking cement mill workers. Int. J. Environ. Res. Public Health 2013, 16, 390-398.

24. Al-Fayez, S.F.; Salleh, M.; Ardawi, M.; Zahran, F.M. Effects of Shisha and cigarette smoking on pulmonary function of Saudi males and females. Trop. Geogr. Med. 1988, 40, 115-123.

25. Hakim, F.; Hellou, E.; Goldbart, A.; Katz, R.; Bentur, Y.; Bentur, L. The acute effects of water-pipe smoking on the cardiorespiratory system. Chest 2011, 139, 775-781.

26. Hawari, F.I.; Obeidat, N.A.; Ayub, H.; Ghonimat, I.; Eissenberg, T.; Dawahrah, S.; Beano, H. The acute effects of waterpipe smoking on lung function and exercise capacity in a pilot study of healthy participants. Inhal. Toxicol. 2013, 25, 492-497.

27. Raad, D.; Gaddam, S.; Schunemann, H.J.; Irani, J.; Abou Jaoude, P.; Honeine, R.; Akl, E.A. Effects of water-pipe smoking on lung function: A systematic review and meta-analysis. Chest 2011, 139, 764-774.

28. Schünemann, H.J.; Jaeschke, R.; Cook, D.J. ATS documents development and implementation committee an official ATS statement: Grading the quality of evidence and strength of recommendations in ATS guidelines and recommendations. Amer. J. Respir. Crit. Care. Med. 2006, 174, 605-614.

29. Boskabady, M.H.; Farhang, L.; Mahmodinia, M.; Boskabady, M.; Heydari, G.R. Comparison of pulmonary function and respiratory symptoms in water pipe and cigarette smokers. Respirology 2012, 17, 950-956.

30. Manna, A.; Caffarelli, C.; Varini, M.; Dascola, C.P.; Montella, S.; Maglione, M.; Sperlì, F.; Santamaria, F. Clinical application of exhaled nitric oxide measurement in pediatric lung diseases. Ital. J. Pediatr. 2012, 31, 38-74.

31. Silverberg, J.I.; Rodenas, M.; Sinert, R.; Joks, R. Emergency department treatment of adults with acute asthma exacerbations: Effect on exhaled nitric oxide levels. Allergy Asthma Proc. 2012, 33 , 514-518.

32. Alving, K.; Malinovschi, A. Basic aspects of exhaled nitric oxide. In Exhaled Biomarkers; Horvath, I., de Jongste, J.C., Eds.; European Respiratory Society: Polymouth, UK, 2010.

33. Jouaville, L.F.; Annesi-Maesano, I.; Nguyen, L.T.; Bocage, A.S.; Bedu, M.; Caillaud, D. Interrelationships among asthma, atopy, rhinitis and exhaled nitric oxide in a population-based sample of children. Clin. Exp. Allergy 2003, 33, 1506-1511.

34. ATS/ERS recommendations for standardized procedures for the online and offline measurement of exhaled lower respiratory nitric oxide and nasal nitric oxide. Amer. J. Respir. Crit. Care Med. 2005, 171, 912-930.

35. Khalili, B.; Boggs, P.B.; Bahna, S.L. Reliability of a new hand-held device for the measurement of exhaled nitric oxide. Allergy 2007, 62, 1171-1174. 
36. Renzetti, G.; Silvestre, G.; D’Amario, C. Less air pollution leads to rapid reduction of airway inflammation and improved airway function in asthmatic children. Pediatrics 2009, 123, 1051-1058.

37. Nickmilder, M.; de Burbure, C.; Carbonnelle, S.; Dumont, X.; Bernard, A.; Derouane, A. Increase of exhaled nitric oxide in children exposed to low levels of ambient ozone. J. Toxicol. Environ. Health. Pt. A 2007, 70(3-4), 270-274.

38. Dales, R.; Wheeler, A.; Mahmud, M.; Frescura, A.M.; Smith-Doiron, M.; Nethery, E.; Liu, L. The influence of living near roadways on spirometry and exhaled nitric oxide in elementary schoolchildren. Environ. Health. Perspect. 2008, 116, 1423-1427.

39. Holguin, F.; Flores, S.; Ross, Z.; Cortez, M.; Molina, M.; Molina, L.; Rincon, C.; Jerrett, M.; Berhane, K.; Granados, A.; et al. Traffic-related exposures, airway function, inflammation, and respiratory symptoms in children. Amer. J. Respir. Crit. Care Med. 2007, 176, 1236-1242.

40. She, J.; Yang, P.; Wang, Y.; Qin, X.; Fan, J.; Wang, Y.; Gao, G.; Luo, G.; Ma, K.; Li, B.; et al. Chinese waterpipe smoking and the risk of chronic obstructive pulmonary disease. Chest 2014, 20, doi:10.1378/chest.13-1499.

41. Nadif, R.; Matran, R.; Maccario, J.; Bechet, M.; le Moual, N.; Scheinmann, P.; Bousquet, J.; Kauffmann, F.; Pin, I. Passive and active smoking and exhaled nitric oxide levels according to asthma and atopy in adults. Ann. Allergy Asthma. Immunol. 2010, 104, 385-393.

42. Barua, R.S.; Ambrose, J.A.; Srivastava, S.; deVoe, M.C.; Eales-Reynolds, L.J. Reactive oxygen species are involved in smoking-induced dysfunction of nitric oxide biosynthesis and upregulation of endothelial nitric oxide synthase: An in vitro demonstration in human coronary artery endothelial cells. Circulation 2003, 107, 2342-2347.

43. Hoyt, J.C.; Robbins, R.A.; Habib, M.; Springall, D.R.; Buttery, L.D.; Polak, J.M.; Barnes, P.J. Cigarette smoke decreases inducible nitric oxide synthase in lung epithelial cells. Exp. Lung Res. 2003, 29, 17-28.

44. Malinovschi, A.; Janson, C.; Holmkvist, T.; Norbäck, D.; Meriläinen, P.; Högman, M. Effect of smoking on exhaled nitric oxide and flow-independent nitric oxide exchange parameters. Eur. Respir. J. 2006, 28, 339-345.

(C) 2014 by the authors; licensee MDPI, Basel, Switzerland. This article is an open access article distributed under the terms and conditions of the Creative Commons Attribution license (http://creativecommons.org/licenses/by/3.0/). 